\title{
THREE-STAND PLTCM: TECHNOLOGY AND FILED RESULTS FROM THE LATEST DANIELI COLD ROLLING INSTALLATION*
}

\author{
Massimilinao Svetina ${ }^{1}$ \\ Luciano Vgnolo $^{2}$ \\ Michele Turchetto ${ }^{3}$
}

\begin{abstract}
In 2010 Danieli \& C. S.p.A. put into operation a new Pickling Tandem Mill in Cremona (Italy) at Acciaieria Arvedi, the last Pickling line coupled Tandem Cold Mill (PLTCM) in Europe. The plant was tailor-made to suit the specific requirements of this customer; a very broad range of sizes and grades (IF to AHSS as well as DP and TRIP1000) including ultra-thin hot band can be processed, achieving a total capacity of $1.6 \mathrm{Mt} / \mathrm{y}$. The Danieli \& C. S.p.A. Turboflo ${ }^{\circledR}$ process was selected because of its proven efficiency and ability to handle ultra-thin gauges at speeds exceeding 400 $\mathrm{mpm}$ in the pickling tanks. All the equipment, i.e. pickling section and rolling mills was provided with the last generation of Danieli market-oriented technologies. Danieli \& C. S.p.A. - with the support of Arvedi and feedback from the field - is continuously improving its technical design solutions and optimizing plant operations.
\end{abstract}

Keywords: PLTCM; TCM; Pickling; Tandem mill; Turboflo ${ }^{\circledR}$; Arvedi; Innovaction.

\footnotetext{
Sales Manager, Danieli Wean United, Italy,

Executive Manager Technology, Danieli Wean United, Italy,

Executive Product Manager, Danieli Wean United, Italy.
} 


\section{INTRODUCTION}

The PLTCM plant installed at Arvedi is quite not an ordinary one in the worldwide panorama, the reason being the high speed and relatively small reduction required in the rolling mill.

The equipment is able to process mild steel, high-strength steel, high-strength lowalloy steel, advanced high-strength steel and non-grain-oriented silicon steel (e.g. cold forming DD12 (EN10111), structural S335x to S420x (EN10025-2/3/4), severe cold forming DP600-800, TRIP800) for non-exposed and exposed applications, for a total capacity of $1.6 \mathrm{Mt} / \mathrm{year}$.

The expected average thickness to be produced by the plant is below $1.5 \mathrm{~mm}$ (in the pickling), with an average rolled thickness of less than $0.5 \mathrm{~mm}$.

A pickling speed of $400 \mathrm{mpm}$ (with about $10 \%$ reserve in the electro-mechanical design) is selected as the one able to achieve an annual output of $1.6 \mathrm{Mt} / \mathrm{year}$, of which $30 \%$ only P\&O coils. The in-line tandem mill is equipped with 3 stands in phase 1 and future provision of one additional "stand 0" in phase 2. The mill has a 6$\mathrm{Hi}$ design, with work and intermediate roll shifting for the future production of silicon steels. A pictorial representation of the plant is given in Figure 1.

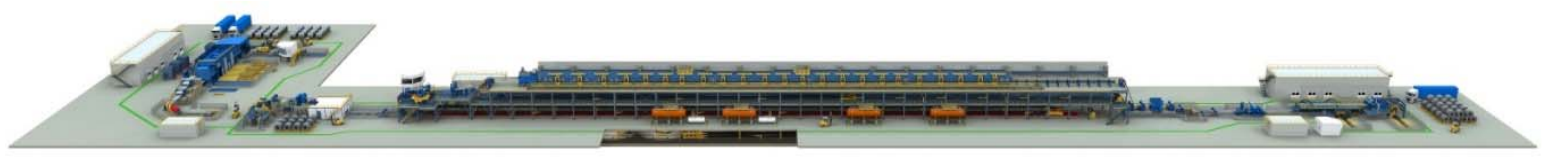

Figure 1: 3D modeling of the line layout

\section{EQUIPMENT}

\subsection{Entry and Pickling Section}

The entry section is designed to have a short entry time with significant shape improvement thanks to the entry flattener (i.e. Scale Breaker) arrangement; the maximum entry speed is $850 \mathrm{mpm}$.

\subsection{Scale Breaker for Ultra-High Strength Steels}

The high-tension scale breaker is designed to achieve a tension of $600 \mathrm{KN}$, which is one and half times more power than the conventional design, but it is essential in order to achieve optimal shape roll improvement for the new generation of advanced high-strength steels (HSS like DP and TRIP) prior to pickling. It has two leveling cassettes and one anti-crossbow cassette. Under normal conditions, one leveling cassette is in operation and the second acts as an installed spare. For extreme, high yield conditions like TRIP 780 or Dual Phase, or thin gauge material, both cassettes are in operation. This machine ensures uniform scale-breaking and improved strip shape; both these aspects are necessary to have a stable, high processing speed. 


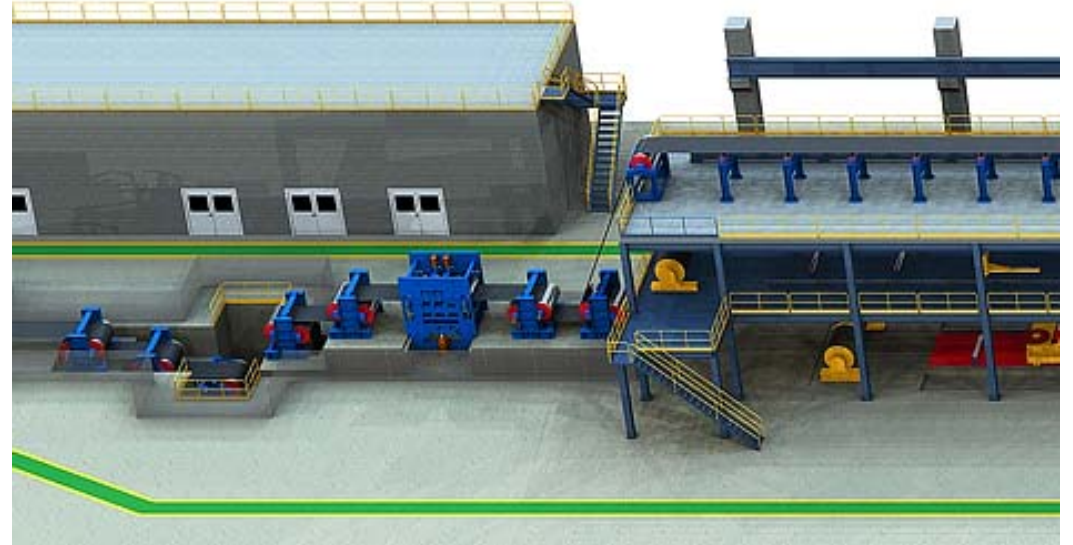

Figure 2: 3D-modeling of high-tension scale breaker

\subsection{Channel-Concept Turboflo® Continuous Pickling Line}

The pickling section consists of four patented Turboflo ${ }^{\circledR}$ channel-type tanks, the only one proven on high speed. The tank has a "turbulence" design, where pickling efficiency comes from break of the laminar flow formed at the interface below and above the strip and the pickling medium: the turbulence generates a high kinetic energy of the acid on the phase boundaries.

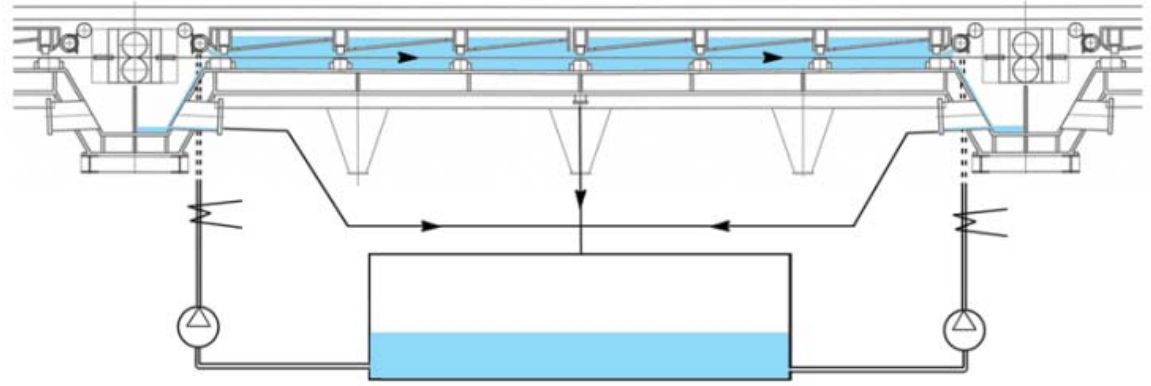

Figure 3: Turboflo® tank with shaped bottom and cover

The turbulence is achieved by an innovative cell concept, which consists of (1) the sprayers located at entry, exit and at sides of each tank, and (2) the changes in the section of pickling channel. Each pickling tank consists of multiple cells approx. 2 meters long. The tank design has proven to be effective and reliable in preventing splashing of acid solution at high speeds. The special cover design captures the surge of pickle liquor - created by the high strip speed - and recirculates it to increase turbulence. This results in no surge of the pickle liquor and consequently no high fluid pressure on the wringer rolls.

The nozzle header provided to seal the pickling chamber ensures that only a small volume of acid is dragged out by the strip. In addition, the wringer rolls ensure the required perfect separation of the cascade. 


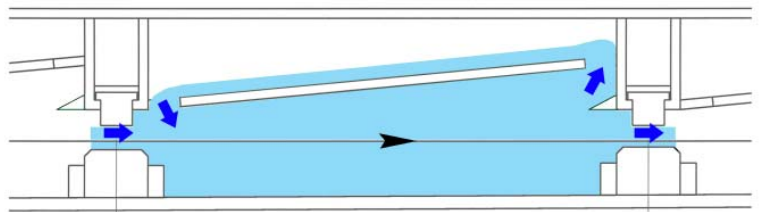

Figure 1: Turboflo® cell.

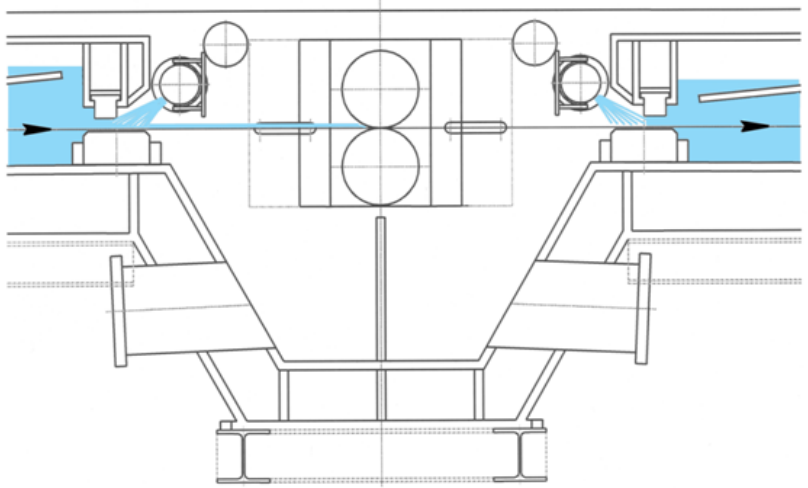

Figure 2: Turboflo® sprayer locations

Since the need to control strip tension is eliminated, high tension can be applied throughout the pickling section, which results in excellent strip tracking.

Thermal efficiency is very high since hot fresh pickle liquor is continuously in contact with the strip surface. Acid is heated by steam in a carbon fiber heat exchanger located on the main pipeline between the recirculation tank and the in-line tank. This system performs a quick check of the acid temperature and generates high heating power that is transmitted to the acid, even at low strip speed, when the highest tonnage per hour of the line is produced.

A larger strip cross-section produces greater turbulence and thus a higher mass transfer rate. This effect, achieved thanks to the cell design and the other design features of the pickling tanks (i.e. recirculation system) has resulted in a significant decrease in steam consumption for acid heating, i.e. at least $10 \%$.

Before plant commissioning, with the support of the Arvedi team, a very detailed examination of the factors influencing the working conditions of the pickling system was done. The analysis gave several indications on the major factors influencing efficiency pickling and sources of energy losses. As a result of this study the minimum pickling time, which was $16 \mathrm{sec}$, has been reduced to approx. $14 \mathrm{sec}$ at the maximum line speed of $450 \mathrm{mpm}$ and an acid temperature of $85^{\circ} \mathrm{C}$.

\subsection{Carousel-type operator-friendly side trimmer}

The new side trimmer and scrap chopper unit trims and chops both edges of the strip; the whole system is mounted on rotating platforms. Safety is the key issue of the innovations applied to this machine.

The two rotating bases are provided to change the side trimmer and scrap chopper heads quickly. Each base is rotated $180^{\circ}$ by a rotary actuator and the travel wheels are driven by a hydraulic motor. The position of the knives is automatically regulated and follows the strip width by means of hydraulic cylinders and position transducers. The two platforms are designed to guarantee the operator easy and safe changing of 
the side trimmer and the scrap chopper knives. The bases when rotated are locked into place by hydraulically operated wedges. The bases are secured in place with hydraulic clamps, to prevent them from rotating or shifting. Two side trimming heads with upper and lower knives are provided for each rotating base. The knives are mounted on idle arbors, which are located with their bearings in eccentric bushings.

The clearance between the upper and lower knives is automatically adjusted by electromechanical screw system. The side trimmer housing is designed to prevent any dangerous operations from being carried out on the machine; this function is controlled by the operator from the control pulpit.

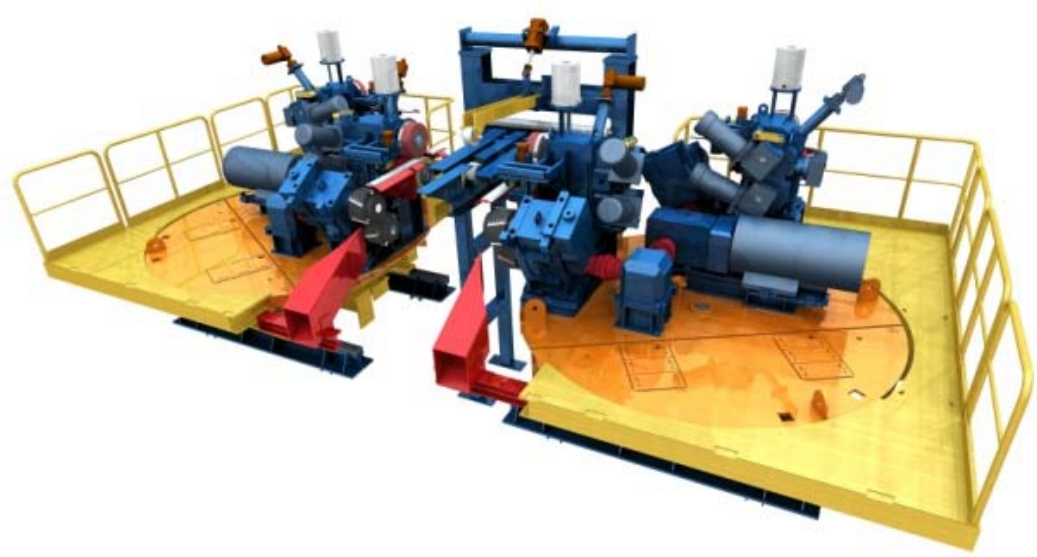

Figure 6: 3D-modeling of the side trimmer

\subsection{Product control at Tandem Mill section}

The common strategy applied by Danieli and Arvedi in designing a cold complex is to have the fastest return on investment. The lowest investment costs in non-steelproducing equipment and the lowest transformation costs are the key parameters for achieving this. Due to space limitations a strip turning device was needed to couple the CPL to the TCM. The helical turning device was selected over the turning tower as there is no need for a large pit or a high building. Minimizing civil works, land usage and coil handling equipment made a helical type turning device the only solution to couple the pickling line with the cold tandem mill, which are in different bays at $90^{\circ}$ to each other.

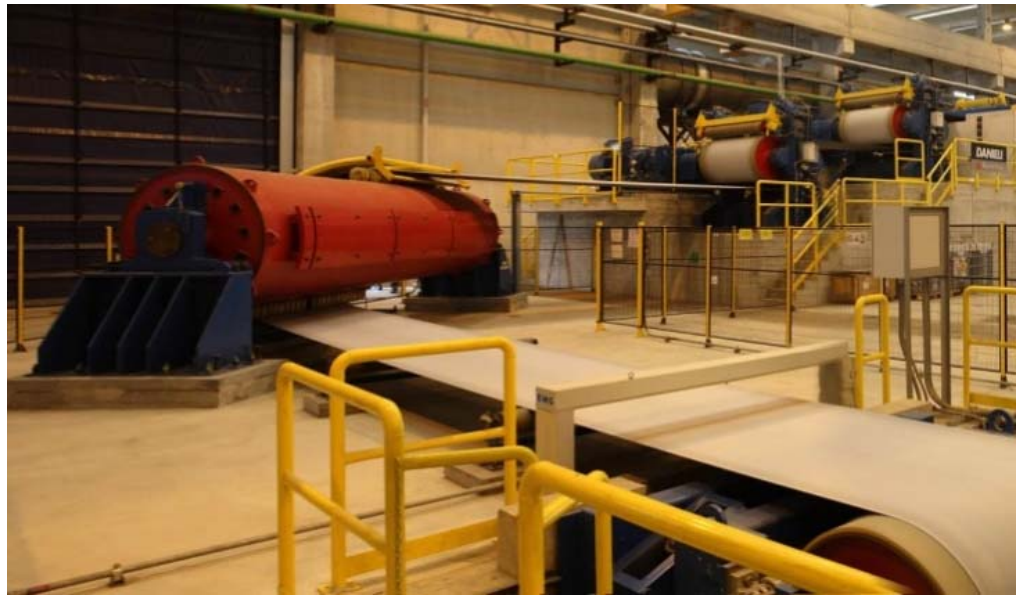

Figure 7: Helical type turning device 


\subsection{High Tandem Mill}

The tandem mill is a three-stand 6-High Mill, with space for the addition of a fourth stands for development new steel grade and is able to achieve more than $80 \%$ strip reduction.

The Danieli three-stand tandem mill processes thin and ultra-thin material in highstrength and dual-phase and TRIP grades, where the flatness performance requires for innovative mechanical design and automation control models.

The cold rolling mill supplied incorporates all the latest developments in this field such as:

$>$ High entry tension;

$>$ Advanced Level 1 thickness and automatic shape control;

$>$ Advanced Level 2 set-up model;

$>$ BUR, IR and WR sensor less eccentricity control in all stands;

$>$ Positive and negative bending;

$>$ Work roll and Intermediate roll shifting

$>$ Edge Drop Compensation;

$>$ Low hysteresis and ultra-fast response time HAGC;

$>$ Recirculation and direct roll coolant system for precise control of friction in cold rolling;

$>$ Patented Confined Jet Dryer ${ }^{\circledR}$ (the ultimate solution for cleanliness and dry exit strip);

$>$ High-speed cutting and carousel coiler;

$>$ Compact inspection and exit coil handling section.

At the entry of the tandem cold mill, there is a system to centre the incoming strip, removing all the errors accumulated in the exit looper with $\pm 5 \mathrm{~mm}$ accuracy. Then, a four-roll bridle is used to control the entry mill tension, filtering all the incoming tension noise from the exit looper with $\pm 2 \%$ in steady state, $\pm 4 \%$ of pre-set value. Finally, a fine steering unit centers the incoming strip just before the roll gap of stand 1 with an accuracy of $\pm 1 \mathrm{~mm}$. Also, before stand 1 there is a three-roll stabilizer to stabilize the strip, increase rolling stability and decrease stand sensitivity, friction and work roll shifting for edge drop control.

The innovative three-stand tandem cold mill has X-ray thickness gauge meters and laser speed meters plus encoders, for redundancy, at entry and exit of stand 1 for the mass flow control model. The exit thickness gauge on stand 1 is also used, together with inter-stand encoders, to monitor and adjust the rolling force on subsequent stands. To ensure an accurate material exit thickness, a double thickness gauge that works in closed-loop feedback with stand 3 and stand 2 has been installed at the exit of stand 3 .

\subsection{Integrated Automatic process Optimization}

When processing different strip widths and thicknesses, a large flatness correction capability is required. Together with the mechanical equipment, such as bending blocks, shifting blocks, as well as roll coolant, flatness performance is achieved by using advanced models such as flatness predictor, the least mean square algorithm, the advanced actuator de-coupling, the force feed forward, the coolant offset analysis and coolant recovery models; all linked to the shape meter at the exit of the last stand for automatic flatness correction, including OSRT on intermediate rolls and tapered work rolls of edge drop control. The entire above are integrated in the 
Automatic Flatness Control (AFC) model, which is based on auto-identification of the best performance of flatness effects, which takes full advantage of the mill's flatness recovery capabilities.

The regulation performances achieved are:

$>$ The advanced control and easy Tunability

$>$ Automatic re-configurability in case of faults

$>$ Sensor-less measurement (i.e. Sensorless Roll Eccentricity compensation).

The Multivariable Control (MVC) technology enhances thickness regulation performance.

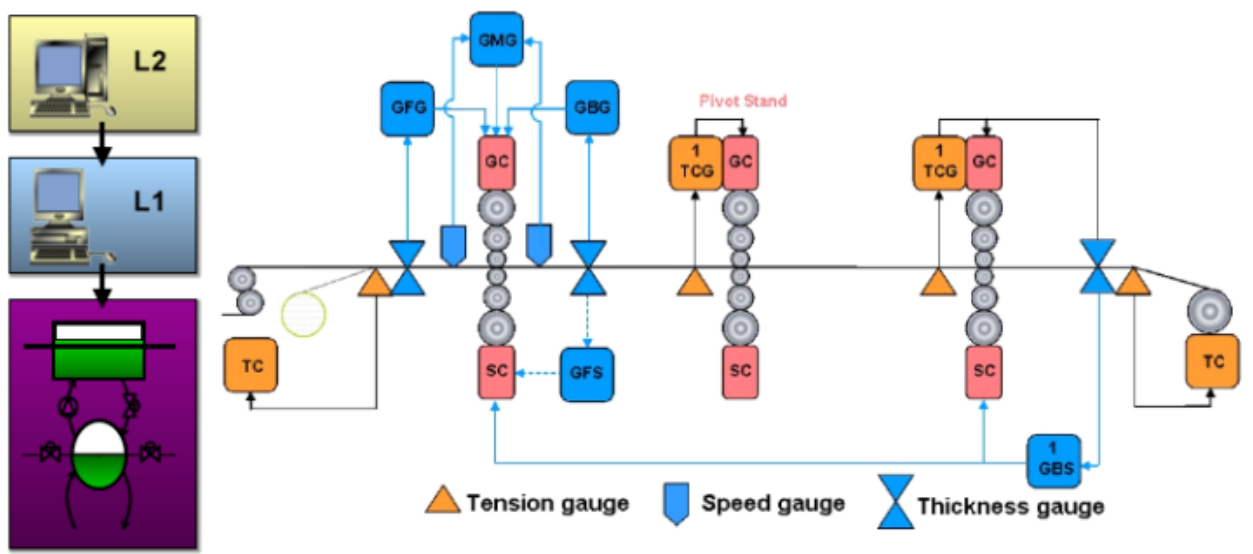

Figure 8: Schematics of electronic integrated instruments for Automatic Flatness Control (AFC)

\subsection{Positive and Negative Bending}

The work and intermediate roll bending system consists of a set of hydraulic cylinders that exert bending forces on the work roll chocks and roll necks. The work and intermediate roll bending system is a two-way type and bending is performed by the same hydraulic cylinder to also achieve the ultra-low and stable bending forces. In the positive bending mode (crown-in), forces are exerted on the work roll chocks in the direction needed to separate them. The work rolls are bent against the backup rolls. In negative bending mode (crown-out), the forces are exerted in the opposite direction. The bending cylinders are located in "C-blocks" mounted on the inside of the housing posts. A specially designed hydraulic control for the bending cylinder prevents instability at the transition between positive and negative bending.

\subsection{Work roll and Intermediate Roll Shifting and Edge Drop Compensation}

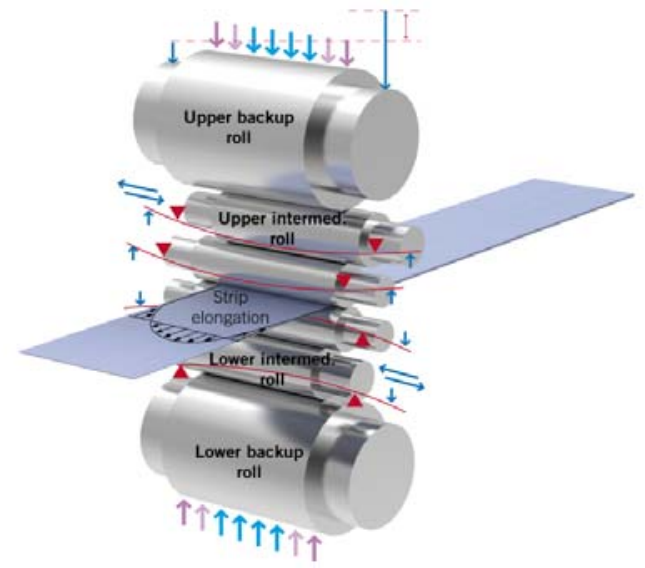

Figure 9: 3D schematics of mill stand 
Long-stroke shifting is performed for both intermediate and work rolls. For intermediate rolls using an OSRT (Optimized Shaped Roll Technology) grinding profile, it enhances the shape control field, while shifting of the tapered work roll is used for Edge Drop Compensation, which is needed for tailor-blank laser welded components for automotive production and electric steels.

By shifting the work roll and intermediate roll bearing life has increased by at least $15 \%$.

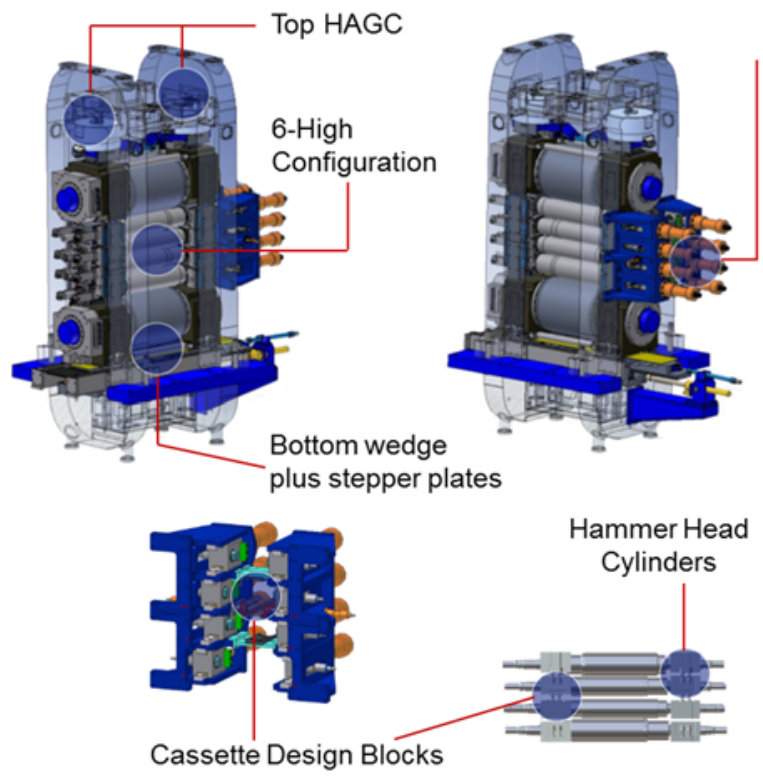

Figure 10: 3D-modelling of work roll and intermediate roll shifting

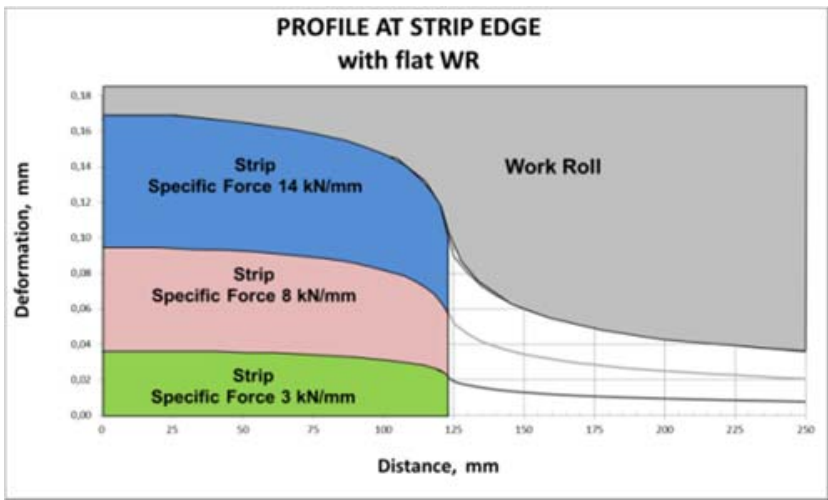

PROFILE AT STRIP EDGE

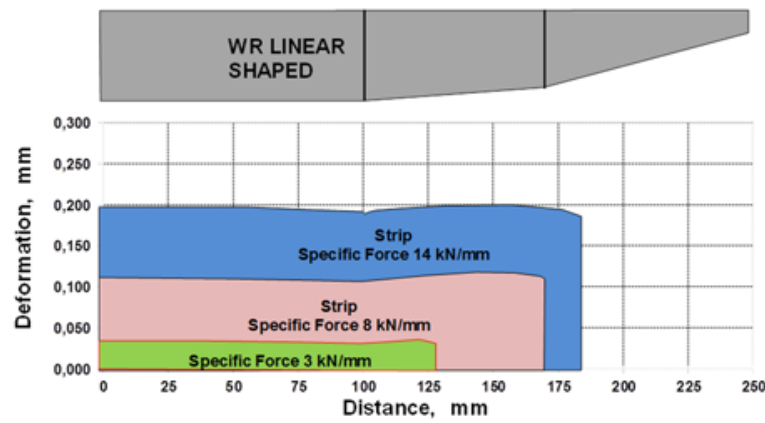

Figure 11: Effects on strip edge with flat work roll 


\subsection{Ultra Low Hysteresis and Ultra-Fast Response Time HAGC}

To guarantee the best performance and comply with the toughest present and future final product market requirements, better performance has been obtained from Hydraulic AGC to improve thickness tolerance. The starting point to achieve better results is to improve the frequency, position and pressure response of the HAGC. The standard system includes hydraulic pressure and flow rate control via servo valve on the bore side and a constant pressure control on the rod side. Danieli Wean United has done thorough research and development in this field, coming up with a new HAGC design with ultra-low hysteresis thanks to reduced friction, new hydraulic control with two servo valves, one for the bore side and the other for the rod side, and new HAGC control software. These innovations made it possible to increase the response times by $45 \%$, i.e. $50 \mu \mathrm{m}$ step @ 22 ms and $20 \mu \mathrm{m}$ step @ $10 \mathrm{~ms}$.

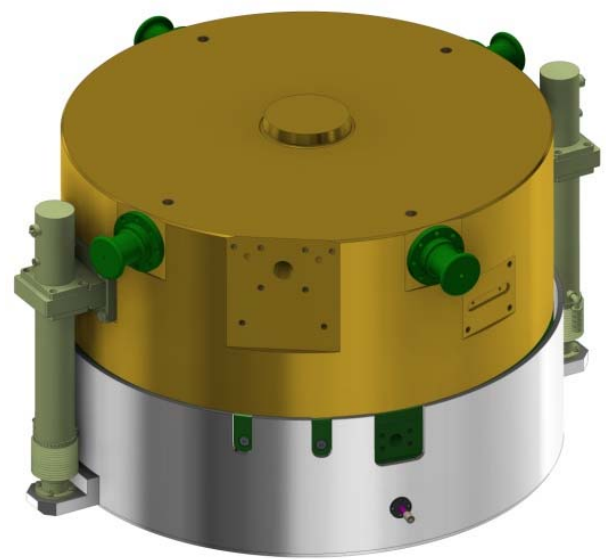

Figure 3: HAGC (Hydraulic Automatic Gap Adjustment)

\subsection{Flexible Rolling Conditions}

A new flexible system developed by Danieli applies lubrication directly to the traditional recirculating system, with benefits in terms of strip surface quality, material yield and mill operation.

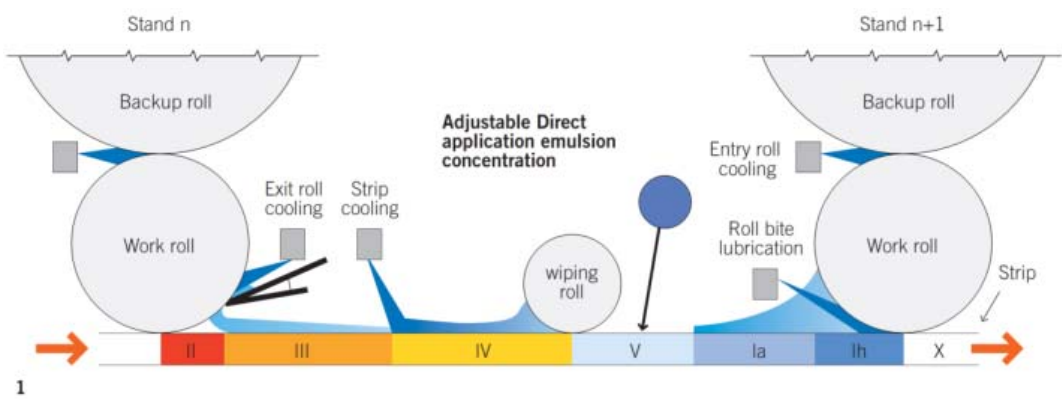

Figure 4: Adjustable Direct application emulsion concentraion

The recirculating roll coolant lubrication system is the standard technology applied to the tandem mill to produce sheet. A stable emulsion system is used to lubricate the bite; at least two separate systems are provided, one for the first two stands and the second for the last one. The limitation of this system is its lack of flexibility when fast changing of steel grades is required. The work roll change the first rolled coils show very poor surface quality and the friction coefficient decreases with the increase in 
mill speed due to the hydrodynamic effect on the roll bite. To mitigate these disturbances, Danieli has developed a new model for Roll-Bite Lubrication by optimizing the Surface Roughness Transfer, based on a mixed lubrication system in which traditional recirculation is enhanced with a direct application capability. This solution makes it possible to dramatically change the lubrication effect, if and when required, keeping the friction coefficient as stable as possible in all mill conditions and improving strip surface appearance after the work roll change. This system achieves the highest operational flexibility as direct applications are possible at any time, independently for each mill stand. The mill automation system controls the use of the two systems, modulating the concentration and application for each stand.

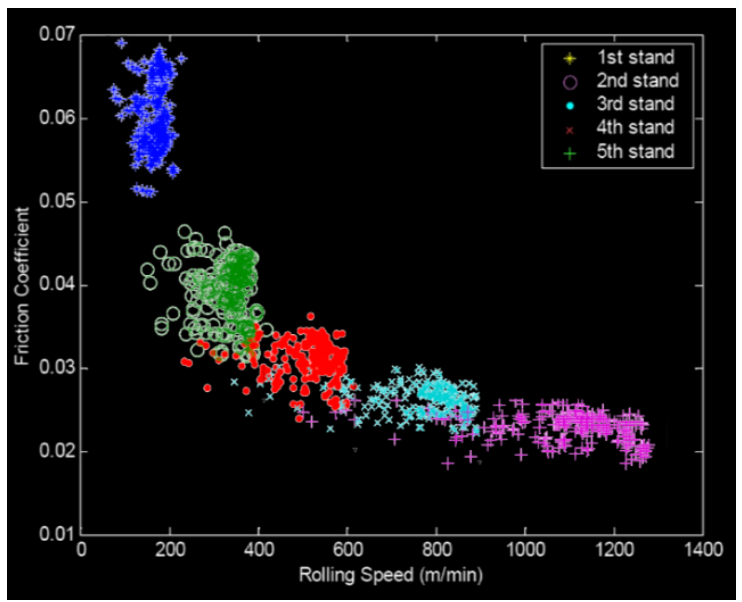

Figure 14: Optimization of Roll bite lubrication

\subsection{Confined Jet Dryer®}

To achieve the highest product quality and surface appearance, an innovative strip drying system was designed. In cold rolling, if there is a solution stain on the strip surface, the material has to be reprocessed or rejected and the part of the coil with the defect is considered as scrap. At present no equipment is available on the market to completely solve this quality issue.

Danieli Wean United, after intensive research and development, has created an innovative device called Confined Jet Dryer ${ }^{\circledR}$ (CJD) that, in addition to the equipment used to seal the exit strip gap of a rolling stand, is able to remove every droplet from the strip surface. This patented equipment is part of a robust drying system designed by Danieli that is easy to install. Because of the small space requirements (less than $0.5 \mathrm{~m}$ ), it can also be installed in existing rolling mills to apply this blow-off method to produce a spotlessly clean rolled strip.

The system operates at the exit of the last stand for the top and bottom surfaces together with the new air blow-off system mounted in the cobble guard. Two air knives are provided for each surface; the first for wiping and the second to confine all the droplets within the machine. Then, these are discharged through a vacuum hood mounted between the two knives. This solution can be applied to all cold rolling processes for sheet thicknesses in the range $0.18-0.30 \mathrm{~mm}$. 


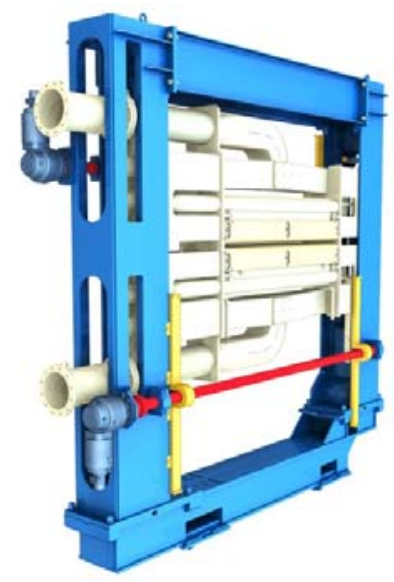

Figure 5: 3D-modeling of Confined Jet Dryer $\AA$

\subsection{High-Speed Exit Section}

The Danieli heavy-duty flying shear, together with the carousel reel, ensures an endless rolling process, with cutting and threading speeds up to $300 \mathrm{~m} / \mathrm{min}$. The flying shear has two drums, top and bottom, which are held in parking position by the electric motor brake. During cutting, the drums are accelerated up to strip speed. Thanks to the Danieli design, all material grades and dimensions can be cut at a maximum speed of $300 \mathrm{~m} / \mathrm{min}$, eliminating excessive mill slowdowns that could cause lower material quality in terms of shape, thickness and surface.

The possibility to cut at high speed and thread a new coil, thus avoiding strip defects in the mill, results from the specially designed carousel reel. The head threading position is extremely short ensuring perfect coiling of the first wraps. The unloading of the finished coil is always performed in the same position, thus simplifying the coil handling system and lowering production costs. In addition, high-speed coil tailing and removal from the carousel will take place 25 seconds after the flying shearing, increasing thick gauge productivity.

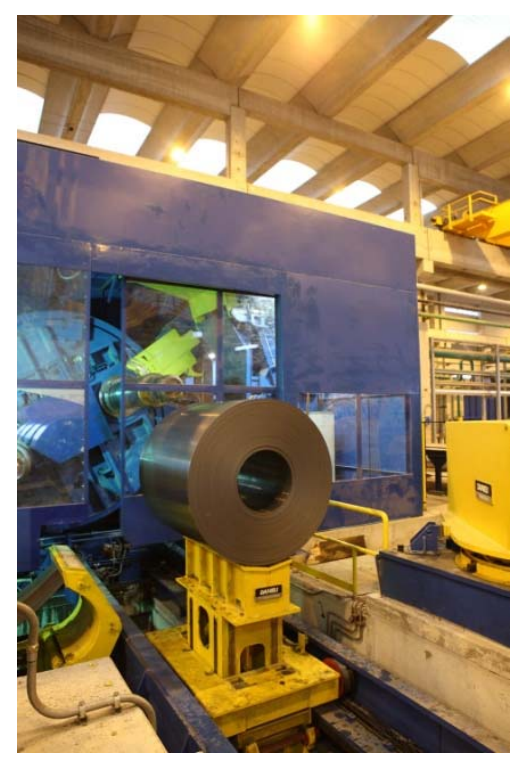

Figure 6: Carousel reel 


\section{CONCLUSIONS}

Thanks to the precise design and high quality of the equipment supplied by Danieli, the plant has been able to produce high-strip quality right from the beginning, with the easy, successful commissioning leading to a fast preliminary and final acceptance of the PLTCM.

Arvedi's possibility of supplying the cold mill with ultra-thin hot band meant that Danieli had to develop a Continuous Pickling Line coupled with a three-stand six-high Tandem Mill, which can produce ultra-thin gauge on cold rolled material, including high-strength steel and advanced high-strength steels. There is a market demand for these materials, which are not yet available, making this a truly innovative plant, and proving once again that Danieli is a leader in the steel industry with its philosophy of innovation in action: "InnovAction".

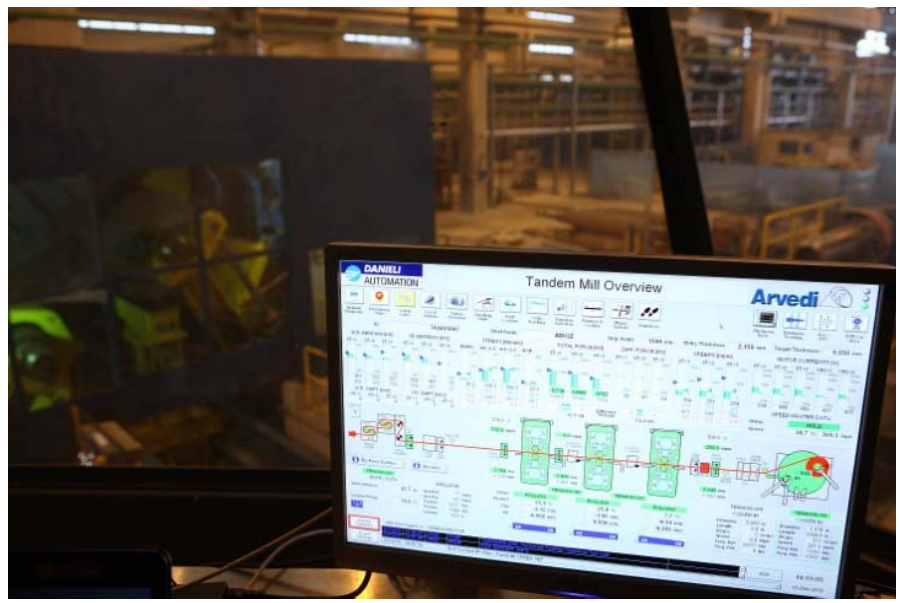

Figure 7: HMI Tandem Cold Mill 